\title{
MITIGASI SAMPAH ANTARIKSA: MENINJAU KESIAPAN REGULASI NASIONAL*
}

\author{
Shannon Suryaatmadja ${ }^{* *}$ \\ Fakultas Hukum, Universitas Katolik Indonesia Atma Jaya \\ Jl. Jenderal Sudirman No. 51, Jakarta 12930
}

\begin{abstract}
The rapid development of space activities has increased the risk of space object collisions in orbit, particularly of space debris. This situation potentially harms satellites and endangers space missions. To date, international efforts generally result in non-legally binding products or soft laws, providing only guidance to form a national legal framework in mitigating space debris. This article aims to review Indonesia's efficacy in regulating its space activities to minimize space debris generation and risks. It also examines mitigation efforts in several other countries with the intention of providing input for the current national legal framework.
\end{abstract}

Keywords: mitigation, space debris, space law.

\section{Intisari}

Pesatnya perkembangan kegiatan antariksa meningkatkan risiko tabrakan antar objek antariksa pada orbit bumi, terutama sampah antariksa. Situasi ini berpotensi merusak satelit hingga membahayakan keberlangsungan misi antariksa. Hingga kini, upaya internasional baru sanggup melahirkan produk hukum tidak mengikat, sehingga hanya mampu mengarahkan negara untuk menyusun kerangka hukum nasional dengan memperhatikan perihal mitigasi sampah antariksa. Artikel ini akan mengkaji kesiapan regulasi nasional untuk meminimalkan risiko timbul dan bertambahnya sampah antariksa. Dibahas pula perbandingan upaya mitigasi pada beberapa negara lain guna memberi masukan bagi Indonesia.

Kata Kunci: hukum antariksa, mitigasi, sampah antariksa.

\section{Pokok Muatan}

A. Pendahuluan 90

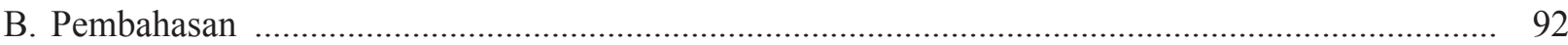

1. Perkembangan Instrumen Hukum Internasional Terkait Mitigasi Sampah Antariksa................. 92

2. Hukum Nasional dan Praktik di Indonesia ........................................................................... 94

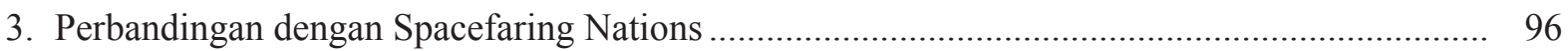

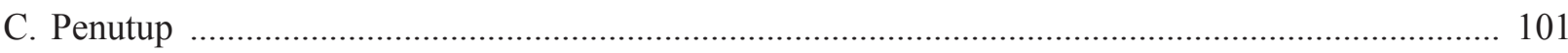

\footnotetext{
Hasil penelitian yang didanai secara mandiri pada tahun 2018-2019. Penelitian dilaksanakan untuk memperkenalkan sekaligus menambah literatur hukum antariksa di Indonesia.

*** Alamat korespondensi: shannon.suryaatmadja@gmail.com.
} 


\section{A. Pendahuluan}

Selama beberapa dekade silam, terdapat sejumlah sampah antariksa yang jatuh ke permukaan bumi terjadi dalam beberapa dekade silam. Pada Januari 1978, Kosmos 954 milik Rusia (Uni Soviet) kembali ke permukaan bumi dan menyebarkan puing radioaktif di Kanada. ${ }^{1}$ Bagian dari roket "FALCON 9 R/B" milik Space X jatuh di Sumenep, Jawa Timur pada 26 September $2016 .{ }^{2}$ Dua kasus tersebut merusak permukaan bumi dan merugikan pihak ketiga.

Isu ini perlu menjadi perhatian serius mengingat eskalasi ketergantungan manusia akan kegiatan antariksa terkait mitigasi bencana alam, pengelolaan sumber daya alam, prakiraan cuaca, telekomunikasi, isu pertahanan dan keamanan, hingga kegiatan perbankan. Sampah antariksa (space debris) merupakan salah satu dampak negatif yang timbul dari pesatnya perkembangan kegiatan antariksa. Jumlah space debris meningkat pesat beberapa tahun belakangan. Lebih dari seratus juta keping sampah antariksa beredar pada orbit bumi berpotensi menimbulkan kerusakan berat pada wahana antariksa atau pada permukaan bumi. ${ }^{3}$

Terakhir, keberhasilan uji coba India menembak satelitnya sendiri pada Maret 2019 berpotensi memperparah keadaan. ${ }^{4}$ Penghancuran satelit melalui misil berarti penambahan jumlah space debris secara signifikan, dan tiap keping berpotensi jatuh ke bumi serta menimbulkan kerugian.
Menyikapi ancaman ini, masyarakat internasional membentuk United Nations Committee on the Peaceful Uses of Outer Space (UNCOPUOS) sebagai komite khusus isu antariksa di bawah United Nations (UN) dan mengambil komitmen memitigasi sampah antariksa guna meminimalkan risiko kerusakan dan kerugian. ${ }^{5}$ Inter-Agency Space Debris Coordination Committee (IADC) mengartikan mitigasi sampah antariksa sebagai seluruh upaya pengurangan sampah antariksa melalui langkah-langkah yang terkait dengan desain, manufaktur, operasi, dan fase pembuangan (disposal phases) dari suatu misi antariksa. Regulasi berperan serta dalam tiap tahap guna mewujudkan komitmen tersebut.

Sejak awal penulisan dimulai, belum ada definisi sampah antariksa yang diakui secara universal, walau dua definisi kerap menjadi rujukan. UNCOPUOS dalam Laporan Teknis Scientific and Technical Subcommittee (STSC) berjudul Technical Report on Space Debris mendefinisikan space debris sebagai benda ciptaan manusia, baik yang berada di orbit bumi maupun yang memasuki atmosfer, yang tidak memiliki fungsi. ${ }^{6}$ Sementara itu, IADC mengartikan space debris sebagai semua objek buatan manusia, termasuk pecahan dan elemen-elemen objek tersebut, yang berada di orbit bumi atau yang memasuki atmosfer kembali. ${ }^{7}$

Dua definisi di atas tidak bertentangan dan berlaku bagi komponen wahana antariksa (space object) ${ }^{8}$ yang lepas atau dibuang seperti

Suzanne Deffree, "Satellite scatters radioactive debris over Canada, January 24, 1978", https://www.edn.com/electronics-blogs/ednmoments/4405598/Satellite-scatters-radioactive-debris-over-Canada--January-24--1978, diakses 21 Februari 2019.

Yunanto Wiji Utomo, "Sosok Falcon 9, Roket yang Puingya Diduga Jatuh di Sumenep", https://sains.kompas.com/read/2016/09/27/09000081/ sosok.falcon.9.roket.yang.puingnya.diduga.jatuh.di.sumenep, diakses 12 Mei 2018.

Kai-Uwe Schrogl, et al., 2018, Space Traffic Mangement: Towards A Roadmap for Implementation, International Academy of Astronautics (IAA), hlm. 54.

Rajat Pandit, "India shoots down live satellite to demonstrate anti-satellite missile capability", http://timesofindia.indiatimes.com/ articleshow $/ 68603800 . \mathrm{cms} ?$ utm source $=$ contentofinterest\&utm medium $=$ text\&utm campaign=cppst, diakses 30 Maret 2019.

The Committee on the Peaceful Üses of Outer Space (COPUOS), 2011, "Forty eighth session: A Report on the International Interdisciplinary Congress on Space Debris", hlm. 5. Dokumen ini menekankan bahwa space debris tidak mudah musnah dan akan tetap meningkat jumlahnya bahkan jika tidak ada lagi peluncuran wahana antariksa lainnya.

UNOOSA Scientific and Technical Subcommittee, Technical Report on Space Debris (UN Doc. A/AC.105/720, 1999), par. 6.

Inter-Agency Space Debris Coordination Committee (IADC), IADC Space Debris Mitigation Guidelines (IADC Guidelines), 2002, par. 3.1.

Pasal 1 angka 8 Undang-Undang Republik Indonesia Nomor 21 Tahun 2013 tentang Keantariksaan mengartikan "wahana antariksa" sebagai "benda buatan manusia yang terkait dengan Keantariksaan dan bagian-bagiannya" (Lembaran Negara Republik Indonesia Tahun 2013 Nomor 133, Tambahan Lembaran Negara Republik Indonesia Nomor 5435). 
lempengan besi, baut, mur, bahkan serpihan cat. Ketidakberadaan definisi universal menunjukkan absennya perhatian yang dalam terhadap isu ini hingga beberapa dekade silam. Namun, hukum antariksa yang ada masih memberikan kerangka awal untuk upaya regulasi dalam mitigasi space debris.

Terdapat lima konvensi tentang hukum antariksa (space treaties), yakni Treaty on Principles Governing the Activities of States in the Exploration and Use of Outer Space, including the Moon and Other Celestial Bodies 1967 (OST), Agreement on the Rescue of Astronauts, the Return of Astronauts and the Return of Objects Launched into Outer Space 1968 (ARRA), Convention of International Liability for Damage caused by Space Objects 1972 (LIB), Convention on Registration of Objects Launched into Outer Space 1975 (REG), dan Agreement Governing the Activities of States on the Moon and Other Celestial Bodies 1979 (MOON). Kelimanya tidak mengatur space debris secara eksplisit, tetapi telah menyuarakan pentingnya memitigasi dampak buruk kegiatan antariksa.

OST selaku magna charta hukum antariksa menyatakan bahwa segala aktivitas ruang angkasa tidak boleh menimbulkan interferensi dan bahaya kontaminasi terhadap lingkungan bumi dan atmosfer.' Pasal IV menyatakan bahwa negara bertanggung jawab atas setiap kegiatan antariksa yang dilakukannya. ${ }^{10}$ Tanggung jawab (responsibility dan liability ${ }^{11}$ ) jatuh pada otoritas peluncur wahana antariksa. ${ }^{12}$ Kemudian Pasal 1 LIB menjelaskan bahwa negara yang melucurkan atau memfasilitasi peluncuran wahana antariksa dalam yurisdiksinya menjadi subjek hukum yang memikul tanggung jawab; bahkan jika peluncuran gagal. Subjek hukum tersebut dihadapkan dengan kewajiban pemberian kompensasi kepada pihak yang mengalami kerugian akibat segala kerusakan yang dideritanya. ${ }^{13}$

REG mewajibkan registrasi wahana antariksa untuk melacak dan mengidentifikasi space debris sebagai akses untuk meminta ganti rugi kepada negara peluncur. Data mengenai peluncuran dan operasi wahana antariksa kepada Sekretaris Jenderal $\mathrm{PBB}^{14}$ guna mengurangi potensi tabrakan antar satelit atau wahana antariksa serta mengurangi pertumbuhan jumlah sampah antariksa. Sejauh ini, baru Amerika Serikat dan Rusia yang mengoperasikan radar termutakhir guna memonitor orbit bumi secara komprehensif (space situational awareness). ${ }^{15}$

Space treaties hanya mengatur kegiatan keantariksaan secara normatif dan umum. Hak dan kewajiban negara dijabarkan, tetapi pelaksanaannya dalam konteks mitigasi sampah antariksa tidak memiliki arahan pasti maupun dorongan seperti pembentukan protokol. Belum ada instrumen hard law yang menjabarkan jenis-jenis upaya mitigasi untuk menyikapi space debris secara spesifik beserta konsekuensi yang ditanggung selain kompensasi pada pihak ketiga.

Pasal IX (b) Treaty on Principles Governing the Activities of States in the Exploration and Use of Outer Space, including the Moon and Other Celestial Bodies 1967.

10 Pasal 8 lebih lanjut menjelaskan kegiatan keantariksaan yang dilaksanakan badan non-pemerintah harus memperoleh izin dan pengawasan secara berkelanjutan oleh pemerintah. Ibid, Pasal 6.

11 Responsibility memiliki dua elemen: kewajiban melakukan, menghentikan, atau tidak melakukan suatu tindakan; dan attributability, yakni bilamana tindakan dapat dihubungkan dengan suatu pihak. Ruang lingkup liability lebih spesifik, yakni kewajiban untuk mengganti kerugian pihak ketiga. von der Dunk dan Frans G., 1992, "Liability versus Responsibility in Space Law: Misconception or Misconstruction?", dipublikasikan di Proceedings of the 34th Colloquium on the Law of Outer Space, hlm. 366-367.

12 Otoritas peluncur dapat berupa negara atau organisasi internasional. Menurut Pasal 8 Treaty on Principles Governing the Activities of States in the Exploration and Use of Outer Space, including the Moon and Other Celestial Bodies 1967 (OST), organisasi internasional yang memegang otoritas harus menerima hak dan kewajiban sebagaimana termuat dalam OST, dan mayoritas negara anggota organisasi internasional tersebut merupakan negara penandatangan OST.

13 Kerugian dalam Pasal 1 Convention of International Liability for Damage caused by Space Objects 1972 (LIB) dapat berbentuk kematian, luka-luka atau bentuk gangguan kesehatan lainnya, hilang atau rusaknya harta milik individu, badan hukum, negara, atau organisasi internasional antar pemerintah.

14 Pasal 4 Convention on Registration of Objects Launched into Outer Space 1975.

15 Per Januari 2014, Amerika Serikat dapat memonitor 16.000 objek pada saat bersamaan. Rusia menyusul dengan angka dibawahnya. Corinne Contant-Jorgenson, et.al. (Eds.), 2006, Cosmic Study on Space Traffic Management, International Academy of Astronautics, Paris, p. 28. 
Misalnya, Pasal IX OST mewajibkan konsultasi internasional sebelum melaksanakan misi antariksa yang dapat menyebabkan interferensi atau kerusakan lingkungan. Namun, konsultasi hanya diwajibkan bila ada pihak yang menyadari ancaman tersebut. Tanpa diseminasi informasi, maka pihak ketiga belum tentu memahami dampak suatu misi antariksa dan tidak mampu memutuskan perlu tidaknya konsultasi.

Sebagai contoh lain, REG tidak mewajibkan disediakannya data terkini mengenai perpindahan orbit wahana antariksa. Padahal, objek antariksa yang berpindah orbit akan melewati orbit wahana antariksa lain tanpa kendali pasti dan menimbulkan potensi tabrakan yang tinggi. ${ }^{16}$

Keadaan terkini mengakibatkan ambiguitas akan keakuratan data sebagaimana termuat dalam United Nations Registry. Kesuksesan mitigasi sampah antariksa bergantung pada itikad baik setiap pihak.

Artikel ini akan membahas upaya mitigasi dari perspektif masyarakat internasional, meliputi hukum positif beserta implementasinya, terutama yang dilakukan oleh Indonesia.

\section{B. Pembahasan}

1. Perkembangan Instrumen Hukum Internasional Terkait Mitigasi Sampah Antariksa

Inter-Agency Space Debris Coordination
Committee ${ }^{17}$ Space Debris Mitigation Guidelines (IADC Guidelines) merupakan salah satu instrumen utama yang berkonsentrasi pada isu mitigasi sampah antariksa. Panduan ini membahas perencanaan, perancangan, dan peluncuran wahana antariksa untuk meminimalkan timbulnya puing selama dan sesudah kegiatan operasional berlangsung.

IADC Guidelines menyoroti orbit yang vital bagi kegiatan antariksa, yakni Low-Earth Orbit (LEO) dan Geostationary Orbit (GEO). Saat wahana antariksa telah mendekati masa End of Life (EOL), operator perlu melakukan passivation; ${ }^{18}$ kemudian merelokasi dari LEO dan GEO menggunakan metode de-orbit ${ }^{19}$ atau re-orbit ${ }^{20}$ agar tidak mengganggu kegiatan antariksa lain. ${ }^{21}$ Dalam implementasinya sejak 1997 hingga 2007, terdapat 134 upaya relokasi satelit yang telah mencapai masa EOL dengan 60 keberhasilan; sepuluh satelit berhasil dipindahkan ke area sekitar 250kilometer diatas GEO; serta 64 kegagalan akibat kendala teknis. $^{22}$

UN juga memiliki panduan yang dibentuk COPUOS. $^{23}$ Isu penanggulangan space debris beberapa kali dibahas pada Legal Sub-Committee (LSC) dari perespektif nasional nasional dan penerapan non-legally binding instrument. ${ }^{24}$ Adalah Space Debris Mitigation Guidelines of the Committee on the Peaceful Uses of Outer Space 2007 (UN Guidelines) ${ }^{25}$ yang menjabarkan berbagai bentuk mitigasi secara normatif.

16 Vladimir M. Agapov, "National Space Law and Policy of the Russian Federation”, dipresentasikan di UN/CHINA/APSCO Workshop on Space Law, Beijing, 18 November 2014, http://www.unoosa.org/documents/pdf/spacelaw/activities/2014/pres12E.pdf, 4 Januari 2019.

17 IADC merupakan forum koordinasi internasional antarbadan pemerintah mengenai isu sampah antariksa. Tujuan utamanya ialah untuk bertukar informasi mengenai aktivitas penelitian, memfasilitasi peluang kerja sama dalam penelitian, meninjau kemajuan kegiatan kooperasi yang sedang berlangsung, dan mengidentifikasi opsi mitigasi puing-puing antariksa. IADC, "Welcome to the Inter-Agency Space Debris Coordination Committee Website", https://www.iadc-online.org/, diakses 31 Desember 2018.

18 Passivation adalah pembuangan atau pemadaman sumber tenaga internal wahana antariksa agar tidak mengakibatkan ledakan yang dapat menimbulkan sampah antariksa.

19 Manuver untuk mengembalikan wahana antariksa (umumnya di daerah LEO) ke bumi agar wahana dapat terbakar habis oleh panas atmosfer. IADC memberikan jangka waktu 25 tahun untuk memindahkan wahana antariksa di daerah LEO setelah masa operasional berakhir.

20 Wahana dipindahkan ke orbit dengan ketinggian ideal $300 \mathrm{~km}$ dan minimum $235 \mathrm{~km}$ di atas GEO ("graveyard/disposal orbit"). Re-orbit dilakukan pada objek di GEO dengan biaya relatif rendah.

21 IADC Guidelines, hlm. 6.

22 Martha Mejia-Kaiser, Informal Regulations and Practices in the Field of Space Debris Mitigation, Air and Space Law, Vol. 34, Kluwer Law International BV, 2009, hlm. 30 .

23 Christopher D. Johnson, Committee on the Peaceful Uses of Outer Space: History, Structure, Agenda, and Current Work, dipresentasikan di Georgetown University Law Center tanggal 12 April 2017, https://swfound.org/media/205800/chris-johnson-copuos-lecture-at-georgetownuniversity-law-center-april-2017.pdf, diakses 30 Desember 2018.

24 Keterangan didapatkan dari Nova Maulani (korespondensi personal), Pejabat Fungsional Diplomat di Direktorat Hukum dan Perjanjian Kewilayahan, Kementerian Luar Negeri Republik Indonesia, tanggal 29 Desember 2018.

25 Panduan ini diadopsi di sesi ke-44 STSC tahun 2007 (A/AC.105/890, par. 99), didukung COPUOS di sesi ke-50 tahun 2007 (A/62/20, par. 118-119), lalu diserahkan ke UNGA dan diterima dalam Resolusi 62/217 tanggal 22 Desember 2007. 
Dokumen ini menekankan bahwa setiap negara memiliki kebebasan untuk mengupayakan mitigasi berdasarkan kapasitas masing-masing.

Kanada, Republik Ceko, dan Jerman berinisiatif menyusun Compendium of Space Debris Mitigation Standards Adopted by States and International Organizations (Compendium) yang diperbarui tiap tahunnya. ${ }^{26}$ Standar ini merefleksikan praktik negara-negara dan organisasi internasional mengenai perencanaan misi antariksa dan pengoperasian wahana.

Selain panduan normatif, terdapat pula instrumen mitigasi yang bersifat teknis untuk memandu mitigasi sampah antariksa. Salah satunya dikeluarkan International Telecommunication Union (ITU), yakni Recommendation ITU-R S.1003.2 (12/2010) on Environmental Protection of the Geostationary-Satellite Orbit mengenai panduan pembuangan satelit dari GEO. ${ }^{27}$

Setiap negara memiliki hak yang sama untuk memanfaatkan orbit sehingga interferensi dilarang. ${ }^{28}$ Masalah timbul jika terdapat satelit tidak aktif yang berpotensi bertabrakan dengan satelit aktif, sehingga menganggu dan merugikan kegiatan antariksa pihak lain. Apabila timbul sengketa, penyelesaian dilakukan melalui negosiasi, upaya diplomasi, atau mekanisme lain sebagaimana terdapat dalam perjanjian mengingat Convention of the International Telecommunication Union 1992 tidak mengatur metode penegakan hukum. ${ }^{29}$

Ditinjau dari benua Eropa, European Space Agency (ESA) memiliki European Code of Conduct for Space Debris Mitigation (CoC) yang selaras dengan IADC Guidelines. ${ }^{30}$ Tujuan utama ESA $\mathrm{CoC}$ adalah mengupayakan mitigasi dalam bentuk meminimalisir operational debris, mencegah tabrakan pada lintasan orbit, serta memfasilitasi tahap pembuangan ketika memasuki fase EOL.

ESA juga mengeluarkan Administrative Instruction on Space Debris Mitigation for Agency Projects ${ }^{31}$ yang berlaku retroaktif bagi tiap proyek ESA, khususnya pada fase orbital dan reentry satelit yang telah diluncurkan. Keberadaan kewajiban pemberian informasi, termasuk perilisan operational debris berikut data orbit, mencerminkan perhatian ESA terhadap mitigasi sampah antariksa. ${ }^{32}$

Kemudian Space Debris Mitigation Compliance Verification Guidelines 2015 hadir guna memastikan pemenuhan prasyarat mitigasi sampah antariksa dari segi teknis dan administratif. Sebuah panel khusus didirikan dengan wewenang memberikan rekomendasi "Request for Waiver" bagi penyelenggara kegiatan. ${ }^{33}$

Panduan ESA memiliki dampak dalam menentukan arah misi. Faktanya, 88\% anggaran Satelit XIPE dialokasikan dalam collision avoidance dan re-entry. ${ }^{34}$ Proyek CHEOPS, Athena, dan beberapa lainnya juga dikaji kembali. ${ }^{35}$ Aneka kesulitan teknis menyebabkan inkonsistensi tingkat keberhasilan upaya mitigasi selama dua dekade terakhir, dengan tingkat keberhasilan terendah (5\%) dalam pemenuhan ketentuan EOL payloads di LEO. ${ }^{36}$

26 Compendium dapat diakses melalui http://www.unoosa.org/oosa/en/ourwork/topics/space-debris/compendium.html.

Empat poin inti rekomendasi ini ialah: (a) menekan angka sampah yang dihasilkan penempatan satelit; (b) melakukan segala upaya yang memungkinkan untuk mempersingkat umur puing yang memiliki apogee (titik terjauh dari bumi) di sekitar GEO; (c) memindahkan satelit di orbit GSO sebelum kehabisan bahan bakar; dan (d) pembuangan ke graveyard orbit tidak boleh menyebabkan interferensi pada frekuensi radio satelit aktif.

28 Pasal 32 ayat (2) Convention of the International Telecom munication Union 1992.

29 Pasal 56 Constitution of the International Telecom munication Union 1992.

30 Terdapat ketentuan teknis yang cukup spesifik, misalnya penentuan space debris manager sebagai pengawas guna memastikan keseluruhan proyek telah menaati ketentuan-ketentuan CoC.

Instruksi ini dibentuk tahun 2008 (ESA/ADMIN/IPOL(2008)2) dan diperbarui tahun 2014 (ESA/ADMIN/IPOL(2014)2).

Bag. 2 Annex 1 Administrative Instruction on Space Debris Mitigation for Agency Projects.

33 Waiver akan membebaskan penyelenggara dari konsekuensi pelanggaran ketentuan mitigasi. Diperlukan dasar pembenar yang sesuai berdasarkan masing-masing kasus. Ibid, Bag. 4.

34 Rüdiger Jehn dan Florian Renk, Impact of Space Debris Mitigation Requirements on the Mission Design of ESA Spacecraft, ESA Space Debris Office, hlm. 5, dipresentasikan di $7^{\text {th }}$ European Conference on Space Debris, Darmstadt, Jerman, tanggal 18-21 April 2017, https://conference. sdo.esoc.esa.int/proceedings/sdc7/paper/406/SDC7-paper406.pdf, diakses 4 Januari 2019.

35 Kelajuan memengaruhi ketinggian orbit. Objek di orbit dengan ketinggian tepat akan habis secara alamiah dalam periode 25 tahun. Ibid.

36 ESA Annual Space Environment Report 2017, Bag. 8. 
International Standardization Organization (ISO) adalah organisasi lain yang juga memiliki peraturan teknis mengenai sampah antariksa ${ }^{37}$ dengan mengacu pada codes of conduct IADC, UNCOPUOS, European Space Agency (ESA), serta beberapa peraturan nasional lain. Standar ISO 24113 merupakan landasan utama yang diaplikasikan bagi seluruh elemen benda antariksa tidak berawak yang diluncurkan ke orbit. ${ }^{38}$ Standar ini menyasar roket dan kendaraan peluncur wahana antariksa; ${ }^{39}$ seperti kalkulasi risiko tabrakan, prosedur post-mission disposal, serta penyediaan informasi aplikasi standar ISO. ${ }^{40}$

Beberapa standar ISO memberikan opsi bagi para operator satelit dan industri manufaktur. Pemenuhan ketentuan ISO oleh para penyelenggara kegiatan keantariksaan harus dapat diverifikasi agar memberikan transparansi bagi pihak konsumen dan lembaga regulator. ${ }^{41}$ Hal ini menunjukkan fleksibilitas implementasi standar ISO serta terbukanya kemungkinan memperbarui standar secara berkala untuk mengikuti perkembangan teknologi.

Berdasarkan beberapa instrumen yang telah dibahas, peraturan teknis seperti standar ISO dan regulasi ITU memiliki efektivitas yang lebih nyata ketimbang panduan normatif. Acuan yang lebih pasti dan teruji secara ilmiah membuat banyak negara berkenan mengikuti regulasi tersebut.

Keanggotaan instrumen dan/atau lembaga juga memengaruhi implementasi peraturan. Per tahun 2019, ITU memiliki 193 negara anggota ketimbang 131 negara yang menandatangani atau meratifikasi OST. Keanggotaan ITU tinggi karena teknologi komunikasi vital bagi semua negara. Tiap anggota perlu mematuhi regulasi ITU dan berupaya menjalankan rekomendasi sebaik-baiknya, termasuk ITU-R S.1003.2. Hal ini mengindikasikan bahwa mitigasi sampah antariksa akan mendapat sorotan yang layak jika negara-negara menyadari urgensi status quo.

\section{Hukum Nasional dan Praktik di Indonesia Indonesia menjadi negara ASEAN per-} tama yang memiliki peraturan khusus bidang keantariksaan, yakni Undang-Undang Republik Indonesia Nomor 21 Tahun 2013 tentang Keantariksaan (UU Keantariksaan). Proses perumusannya mempertimbangkan isi empat space treaties yang telah diratifikasi, peraturan teknis seperti regulasi ITU, soft law seperti resolusi United Nations General Assembly (UNGA), serta (best) state practice. ${ }^{42}$

Pasal 2 UU Keantariksaan memuat komitmen dan itikad Indonesia untuk melaksanakan upaya mitigasi space debris. Indonesia ingin mewujudkan keamanan $^{43}$ dan keselamatan penyelenggaraan keantariksaan, menjamin kepentingan generasi kini dan generasi masa depan, serta melindungi negara beserta segenap warga negaranya dari dampak negatif kegiatan antariksa.

Pasal 8 melarang kegiatan yang "mengancam Keamanan dan Keselamatan Penyelenggaraan Keantariksaan termasuk keamanan Benda Antariksa"

37 ISO merupakan badan penetap standar internasional yang terdiri atas badan-badan standardisasi nasional dengan tujuan menjamin kualitas maupun keamanan barang dan jasa. ISO mulai mengadopsi standar mengenai kegiatan keantariksaan sejak tahun 1994 melalui Space Systems and Operations Subcommittee - bagian dari Aircraft and Space Vehicles Technical Committee. Tahun 2003 Sub-Komite ini mendirikan Orbital Debris Coordinating Working Group untuk membahas standar mitigasi puing. ISO, "All About ISO”, https://www.iso.org/about-us.html, diakses 29 Maret 2019; Martha Mejia-Kaiser, Op. cit., hlm. 26.

Compendium, Op. cit., hlm. 71.

39 Sandrine Tranchard, "ISO Standards for A Safer, Cleaner Space", https://www.iso.org/news/2013/10/Ref1784.html, diakses 30 Desember 2018.

Beberapa standar yang belum memasuki tahap entry into force. Compendium, Op. cit., hlm. 69.

1 Martha Mejia-Kaiser, Op. cit., hlm. 27.

42 Ida Bagus Rahmadi Supancana, "How the Progressive Development of Outer Space Law Affects the Formulation of National Space Legislation: The Experience of Indonesia", Air \& Space Law 40 No. 1, Kluwer Law International BV, 2015, hlm. 94-96.

43 Pasal 1 angka 12 Undang-Undang Republik Indonesia Nomor 21 Tahun 2013 tentang Keantariksaan, "Keamanan adalah segala upaya dan komitmen secara internasional bagi setiap Penyelenggara Keantariksaan untuk memelihara dan/atau menjamin pemanfaatan Antariksa dan benda-benda langit lainnya untuk maksud-maksud damai dan tidak menimbulkan kerusakan bagi lingkungan bumi dan Antariksa melalui keterpaduan pemanfaatan sumber daya manusia, fasilitas, dan prosedur". 
serta "dapat mengakibatkan pencemaran dan/atau kerusakan lingkungan hidup bumi dan Antariksa serta membahayakan Kegiatan Keantariksaan termasuk penghancuran Benda Antariksa", mengikuti Pasal IV OST. Pelaksanaannya harus menggunakan fasilitas sesuai ketentuan berlaku. Artinya, peluncuran dan pengoperasian wahana antariksa tidak boleh menimbulkan gangguan keamanan nasional maupun pelanggaran kebijakan luar negeri dan kewajiban Indonesia.

UU Keantariksaan mengatur tuntutan ganti rugi antar pemerintah (government to government) dengan mengacu pada LIB. ${ }^{44}$ Pasal 82 menjelaskan bahwa WNI yang menderita kerugian berhak melakukan gugatan melalui jalur pengadilan, arbitrase, atau penyelesaian sengketa lainnya. Pemerintah akan memfasilitasi pengajuan gugatan dan penyelesaian ganti rugi.

Penggunaan satelit membuat telekomunikasi relevan dengan mitigasi space debris. Pemerintah memegang kendali atas perangkat telekomunikasi termasuk yang digunakan pada orbit seperti satelit, baik yang diperdagangkan, dibuat, dirakit, dimasukkan dan/atau digunakan di wilayah Indonesia. ${ }^{45}$

Indonesia patuh pada regulasi ITU, termasuk dalam pengalokasian kegiatan satelit di orbit. ${ }^{46}$ Peluncuran dan penggunaan satelit harus mematuhi prosedur dan persyaratan pendaftaran yang ditetapkan Kementerian Komunikasi dan Informatika dengan mengacu pada kriteria ITU. ${ }^{47}$
Menteri Komunikasi dan Informatika, selaku Administrasi Telekomunikasi Indonesia ${ }^{48}$, memiliki peran mendaftarkan rencana penggunaan satelit berikut rencana lokasi orbit ke ITU $^{49}$ serta melaksanakan koordinasi dengan negara lain untuk memastikan kelancaran penggunaan satelit. ${ }^{50}$ Direktur Jenderal Pos dan Telekomunikasi berwenang mendaftarkan Filing Satelit ${ }^{51}$ Indonesia ke ITU.

Penyelenggara harus membuktikan kemampuannya mengendalikan dan mengoperasikan satelit (telemetry, tracking and command [TT\&C]). Tiap tahap berlangsungnya proyek satelit dilaporkan pada Menteri Komunikasi dan Informatika sebagai upaya pengawasan untuk menjaga data agar tetap aktual.

Penyelenggara wajib melakukan kerja sama untuk menyelesaikan gangguan yang merugikan pihak ketiga ${ }^{52}$ dan menanggung kerugian akibat gagalnya peluncuran atau pengoperasian satelit ${ }^{53}$. Penting bagi penyelenggara untuk memiliki asuransi mengingat tingginya risiko finansial yang dihadapi.

Kerangka regulasi nasional belum mengindahkan mitigasi sampah antariksa sebagai isu yang mendesak sehingga perlu mendapat perhatian khusus. Hal ini wajar, mengingat materi muatan UU Keantariksaan masih bersifat umum. Namun, pengaturan yang ada secara keseluruhan sesuai dengan himbauan masyarakat internasional. Indonesia telah kelima lima space treaties dengan

44 Pertanggungjawaban akibat benda jatuh diatur dalam Pasal 58-69 Undang-Undang Keantariksaan.

45 Pasal 32 Undang-Undang Republik Indonesia Nomor 36 Tahun 1999 tentang Telekomunikasi (Lembaran Negara Republik Indonesia Tahun 1999 Nomor 154, Tambahan Lembaran Negara Republik Indonesia Nomor 3881).

46 Penjelasan Umum Peraturan Pemerintah Nomor 53 Tahun 2000 tentang Penggunaan Spektrum Frekuensi Radio dan Orbit Satelit. (Lembaran Negara Republik Indonesia Tahun 2000 Nomor 108, Tambahan Lembaran Negara Republik Indonesia Nomor 3981).

47 Ketentuan International Telecommunication Union (ITU) termasuk data Informasi Publikasi Awal (Advanced Publication Information/API), Permintaan Koordinasi (Coordination Request/CR), Pemeriksaan Menyeluruh (Due Diligence/RES49), dan Notifikasi (Notification).

48 Pasal 1 Angka 17 Peraturan Pemerintah Nomor 53 Tahun 2000 tentang Penggunaan Spektrum Frekuensi dan Orbit Satelit (Lembaran Negara Republik Indonesia Tahun 2000 Nomor 108, Tambahan Lembaran Negara Republik Indonesia Nomor 3981).

9 Ibid, Pasal 33 jo. Penjelasan Umum.

Ibid, Pasal 16 dan 38.

51 Filing Satelit adalah dokumen teknis dari jaringan sistem satelit dan dokumen lain yang didaftarkan kepada ITU untuk dapat menggunakan satelit di orbit satelit tertentu. Pasal 1 Angka 8 Peraturan Menteri Komunikasi dan Informatika Nomor 21 Tahun 2014 tentang Penggunaan Spektrum Frekuensi Radio untuk Dinas Satelit dan Orbit Satelit (Berita Negara Republik Indonesia Tahun 2014 Nomor 1013).

52 Peraturan Pemerintah Nomor 53 Tahun 2000 tentang Penggunaan Spektrum Frekuensi dan Orbit Satelit, Op. cit., Pasal 51.

53 Ibid, Pasal 50. 
pengecualian MOON, serta mendukung implementasi IADC Guidelines dan ITU-R.S.1003.2.54

Terdapat sejumlah Peraturan Pemerintah yang perlu dibentuk sesuai amanat UU Keantariksaan dengan materi muatan terkait penginderaan jauh, teknologi sensitif, asuransi, kriteria peluncuran, mekanisme ganti rugi, peran serta masyarakat, standar keamanan dan keselamatan, bandar antariksa, sanksi administratif, dan komersialisasi keantariksaan. ${ }^{55}$ Indonesia perlu menggunakan kesempatan ini untuk mengikutsertakan ketentuan perihal mitigasi sampah antariksa sebagai perhatian nasional.

Selain upaya mitigasi dalam ranah hukum, Indonesia juga aktif dalam forum internasional. Indonesia rutin menghadiri pertemuan-pertemuan UNCOPUOS dan beberapa organisasi regional. Dalam sesi ke-61 UNCOPUOS (2018), delegasi Indonesia menyatakan perlunya deteksi, pengawasan, pengurangan, dan pemusnahan sampah antariksa. ${ }^{56}$

Di tingkat regional, Indonesia memantau kegiatan Asia-Pacific Space Cooperation Organization (APSCO) $)^{57}$ dan Asia-Pacific Regional Space Agency Forum (APRSAF). Beberapa kementerian dan lembaga penelitian Indonesia serta Lembaga Antariksa dan Penerbangan Nasional (LAPAN) ${ }^{58}$ rutin menghadiri pertemuan tahunan APRSAF dan memberikan presentasi. APRSAF juga memiliki Working Group (WG) mengenai teknologi keantariksaan dengan fungsi data sharing dan capacity building antar negara anggota, termasuk teknologi mitigasi sampah antariksa. ${ }^{59}$

\section{Perbandingan dengan Spacefaring Nations}

Keempat spacefaring nations berikut memiliki standar praktik mitigasi sampah antariksa yang komprehensif, sehingga ideal menjadi pembanding guna memberi masukan bagi Indonesia.

a. Amerika Serikat

Upaya mitigasi space debris AS dipayungi United States Government Orbital Debris Mitigation Standard Practices (Standard Practices) $^{60}$ tahun 2001.61 Implementasinya dilakukan oleh beberapa lembaga dengan pembagian wewenang berdasarkan bidang masing-masing.

Koordinasi kegiatan antariksa AS, termasuk mitigasi space debris, dilakukan National Aeronautics and Space Administration (NASA). Terdapat aturan teknis mengenai sistem pelaporan dan dokumentasi personel dalam memitigasi space debris ${ }^{62}$ serta peraturan internal

Compendium, Op. cit., hlm. 32.

55 Materi yang telah menjadi produk hukum resmi barulah Peraturan Pemerintah Nomor 11 Tahun 2018 tentang Tata Cara Penyelenggaraan Kegiatan Penginderaan Jauh. Kesembilan poin lain masih dalam tahap penyusunan Rancangan Peraturan Pemerintah (RPP). Runggu Prilia Ardes, et al., "Pertimbangan Yuridis dan Konsekuensi Pengelompokan RPP sebagai Amanat Undang-Undang Nomor 21 Tahun 2013 tentang Keantariksaan", hal. 87, https://puskkpa.lapan.go.id/files arsip/Runggu_Pertimbangan_Yuridis 20162.pdf, diakses 10 Januari 2019.

56 Keterangan didapatkan dari Nova Maulani (korespondensi personal), Pejabat Fungsional Diplomat di Direktorat Hukum dan Perjanjian Kewilayahan, Kementerian Luar Negeri Republik Indonesia, tanggal 29 Desember 2018.

57 Indonesia menghadiri acara-acara APSCO, tetapi belum menjadi anggota tetap karena belum meratifikasi Konvensi APSCO. Keterangan didapatkan dari Nova Maulani dan Renny Meirina (korespondensi personal), Pejabat Fungsional Diplomat di Direktorat Hukum dan Perjanjian Kewilayahan, Kementerian Luar Negeri Republik Indonesia, tanggal 24 Januari 2019.

58 LAPAN dibentuk berdasarkan Keputusan Presiden Nomor 236 Tahun 1963 tentang LAPAN tanggal 27 November 1963 sebagai focal point kegiatan antariksa Indonesia yang bertugas melaksanakan penelitian dan pengembangan kedirgantaraan serta menyelenggarakan kegiatan antariksa sesuai ketentuan yang berlaku. LAPAN, "Tugas Pokok dan Fungsi", https://lapan.go.id/index.php/subblog/pages/2013/5/TugasPokok-dan-Fungsi, diakses 12 Januari 2019.

59 APRSAF, “Space Technology Working Group”, http://aprsaf.org/working_groups/st/, diakses 3 Maret 2019.

60 Standard Practices memuat ketentuan umum tentang seluruh tahap kegiatan antariksa. Empat poin utamanya ialah: meminimalkan timbulnya sampah antariksa yang disengaja, meminimalkan probabilitas ledakan yang tidak disengaja, penghindaran tabrakan yang berbahaya, dan pembuangan perangkat keras yang bertanggung jawab. Presidential Policy Directive 4 (PPD-4), National Space Policy (2010) memandatkan AS untuk menaati Standard Practices dengan mempertimbangkan efektivitas biaya.

61 Compendium of Space Debris Mitigation Standards Adopted by States and International Organizations (Compendium), Op. cit., hlm. 57.

62 NASA Procedural Requirements for Limiting Orbital Debris (NPR) bernomor NPR 8715.6A (2007, direvisi 2009). NPR dirumuskan sebagai cerminan praktik mitigasi selama 20 tahun dan berlaku tanpa pengecualian. Fabio Tronchetti, 2013, Fundamentals of Space Law and Policy, Springer, hlm. 49. 
berisi penjabaran teknis yang lebih spesifik mengenai Standard Practices ${ }^{63}$. NASA juga mengemban mandat riset dan pengembangan teknologi antariksa, termasuk meneliti praktik industri swasta guna memberi rekomendasi terbaik untuk melindungi kepentingan AS, misalnya dalam membentuk standar keamanan. ${ }^{64}$

Lisensi operator telekomunikasi komersial jatuh pada Federal Communications Commission (FCC) ${ }^{65}$ Sementara itu, lisensi peluncuran dan re-entry wahana antariksa komersial dipegang Office of Commercial Space Transportation, Federal Aviation Administration (FAA) ${ }^{66}$ Pemohon lisensi harus memastikan bahwa wahana antariksa di masa akhir peluncuran ${ }^{67}$ (end of launch) tidak akan meledak atau membahayakan kegiatan antariksa lain sehingga menimbulkan space debris. $^{68}$

AS menyadari pentingnya mengatur industri antariksa swasta yang berkembang pesat sehingga mengeluarkan U.S. Commercial Space Launch Competitiveness Act 2015. Produk hukum ini mengukuhkan pentingnya melakukan mitigasi sampah antariksa demi melindungi aset antariksa AS. ${ }^{69}$

Kompleksitas regulasi antariksa AS menuntut koordinasi yang berjalan dengan cukup baik. Sektor swasta selalu menjadi pemangku kepentingan yang dipikirkan dalam perumusan regulasi. Selain itu, pembaruan berkala dilakukan mengikuti kemajuan teknologi di bawah koordinasi NASA.

b. Rusia

Minat Rusia dalam mitigasi space debris ditandai oleh partisipasinya dalam perumusan IADC Guidelines serta $U N$ Guidelines. Lembaga antariksa nasionalnya, Russian Federal Space Agency (Roscosmos), memiliki standar operasional mitigasi sampah antariksa yang selaras dengan panduan IADC.

Rusia menerapkan GOST (General Requirements to Spacecraft and Orbital Stages on Space Debris Mitigation) R $52925-2018^{70}$. Standar ini berlaku dalam tahap desain, manufaktur, peluncuran, pengoperasian, dan pembuangan wahana antariksa. $^{71}$

Liability diatur dalam Law of the Russian Federation About Space Activity (1993). Penyelenggara wajib memiliki asuransi yang mencakup kerusakan pada kehidupan dan kesehatan manusia, bendabenda insfrastruktur antariksa, dan kerusakan yang diderita pihak ketiga. Premi asuransi ditransfer ke Russian Space Fund atau

63 NASA Process for Limiting Orbital Debris (Standar 8719.14A) menjabarkan ketentuan adminstrasi proyek, termasuk jangka waktu pelaporan dan penyampaian dokumen terkait proyek tersebut. Pengecualian implementasi Standar 8719.14A dapat dilakukan manajer NASA dengan memberi justifikasi untuk masing-masing kasus.

64 Bagian 111 U.S. Commercial Space Launch Competitiveness Act; American Institute of Aeronautics and Astronautics (AIAA), "Ensuring U.S. Leadership in Space", https://www.aiaa.org/uploadedFiles/Whats New/EnsuringUSLeadershipInSpace FINAL.pdf, diakses 12 Januari 2019.

65 FCC meregulasi komunikasi dengan media radio, televisi, telegram, dan satelit.

66 Compendium, Op. cit., hlm. 58.

67 Titik akhir keberadaan kendali atas kendaraan peluncur wahana antariksa (termasuk reusable launch vehicle atau RLV).

68 Bagian 471.129 Regulasi FAA (Safety at end of launch).

69 Bagian pertama (Spurring Private Aerospace Competitiveness and Entrepreneurship Act of 2015 [SPACE Act 2015]) memandatkan kalkulasi risiko kerugian kegiatan antariksa untuk memastikan efisiensi biaya. Bagian 102 SPACE Act 2015 mencantumkan bahwa Pemerintah AS dan perusahaan peluncur AS harus menanggung risiko finansial serendah mungkin. American Institute of Aeronautics and Astronautics (AIAA), "Ensuring U.S. Leadership in Space", https://www.aiaa.org/uploadedFiles/Whats_New/EnsuringUSLeadershipInSpace_FINAL.pdf, diakses 12 Januari 2019.

70 Peraturan ini menggantikan GOST R 52925-2008 agar isinya selaras dengan ISO 24113. Compendium, Op. cit., hlm. 42.

71 Nurul Sri Fatmawati, Analisis Implementasi Pedoman PBB tentang Mitigasi Sampah Antariksa, Jurnal Analisis dan Informasi Kedirgantaraan, Vol. 9, No. 2, 2012, hlm. 122. 
perusahaan berlisensi sebagai kompensasi dalam bentuk restorasi bagi kerugian yang diderita pihak ketiga. ${ }^{72}$

Guna memastikan efektivitas pengaturan yang ada, Roscosmos memiliki sistem pelaporan yang aktual. Tiap bulan, data yang lolos tahap verifikasi akan dikirimkan melalui Kementerian Luar Negeri Rusia ke PBB. ${ }^{73}$ Automated Warning System on Hazardous Situations in Outer Space (ASPOS OKP) yang mampu mengamati objek di seluruh area GEO dioperasikan sejak 2016 sebagai sistem peringatan akan potensi bahaya. ${ }^{74}$

Implementasi mitigasi telah dilakukan melalui aneka metode. Misalnya, peningkatan kapasitas sistem propelan untuk melakukan manuver di roket jenis Zond, dan penurunan tekanan tangki bahan bakar roket seri Soyuz dan Volga setelah pembuangan ke disposal orbit guna menghindari ledakan. ${ }^{75}$

Berbagai kebijakan Rusia memperlihatkan keinginan untuk memiliki pengaruh lebih pada forum internasional. Rusia terlibat dalam pembentukan aneka instrumen hukum antariksa. Terdapat upaya menyelaraskan hukum nasional dengan instrumen internasional yang diadopsinya melalui pembaruan hukum dan kerja sama internasional. c. Prancis

Prancis telah memiliki instrumen mitigasi space debris sejak 1999, yakni Standards Collection, Method and Procedure Space Debris-Safety Requirements (RNC-CNES-Q-40-512). Isinya meliputi dokumentasi risiko sampah antariksa, dokumentasi tahap EOL, dan daftar dokumen penanda pemenuhan ketentuan mitigasi sampah antariksa. ${ }^{76}$

Tahun 2008, Prancis membentuk French Space Operation Act (FSOA) sebagai bentuk kendali perizinan dan standar teknis kegiatan antariksa yang dilakukan pihak swasta. Otorisasi peluncuran, pengoperasian, pemindahan kendali, dan pendaratan kembali wahana antariksa diberikan jika operator ${ }^{77}$ memiliki kapasitas finansial, moral, dan profesional sesuai ketentuan FSOA. ${ }^{78}$

Implementasi FSOA ditunjang Authorization Decree (AD) dan Technical Regulation (TR $)^{79}$ yang ikut mempertimbangkan risiko sampah antariksa dalam ketentuan teknis untuk pemberian otorisasi atau lisensi. ${ }^{80}$ TR mewajibkan pelaporan analisa dampak lingkungan medan antariksa dan rencana mitigasi dalam keadaan darurat untuk meminimalkan risiko timbul sampah antariksa ${ }^{81}$ Pelanggaran kewajiban operator dapat dikenakan denda ${ }^{82}$ serta penangguhan

72 Anjar Supriadhie, "Penyebab Terjadinya Kerugian dan Tuntutan Tanggung Jawab dalam Penyelenggaraan Keantariksaan", Kajian Kebijakan dan Hukum Kedirgantaraan 2015, Jakarta: Mitra Wacana Media, 2015, hlm. 148-150.

73 Vladimir M. Agapov, "National Space Law and Policy of the Russian Federation", dipresentasikan di UN/CHINA/APSCO Workshop on Space Law, Beijing, 18 November 2014, http://www.unoosa.org/documents/pdf/spacelaw/activities/2014/pres12E.pdf, 4 Januari 2019.

74 Roscosmos, "Activities of the Russian Federation on Space Debris Research in 2016", dipresentasikan di sesi ke-55 STSC COPUOS, 30 Januari - 10 Februari 2017, http://www.unoosa.org/documents/pdf/spacelaw/activities/2014/pres12E.pdf, diakses 4 Januari 2019.

75 Ibid.

76 Lihat presentasi Fernard Alby dari CNES berjudul "Overview on 2011 Space Debris Activities in France" melalui http://www.unoosa.org/pdf/ pres/stsc2012/tech-23E.pdf.

77 "Operator" tidak termasuk Kementerian Pertahanan Prancis, industri manufaktur satelit, maupun kegiatan CNES. Pengecualian ini tertera dalam Pasal 26-27 FSOA.

78 Terdapat pula lisensi dengan notifikasi jangka waktu operator untuk memenuhi prasyarat agar mendapat otorisasi. Lisensi juga berfungsi sebagai otorisasi dalam operasi tertentu.

9 Decree on Technical Regulation issued pursuant to Act No. 2008-518 of 3rd June 2008.

80 Otorisasi diterbitkan oleh Menteri (Pasal 1 AD) sementara TR dievaluasi oleh CNES.

81 Philippe Clerc, "The French Space Operations Act”, https://olemiss.edu/programs/spacelaw/events/pdfs/2011/clerc-presentation-galloway. $p d f$, diakses 1 Januari 2019.

82 Tindakan-tindakan yang dapat didenda jika dilakukan tanpa izin berdasarkan Pasal 11 FSOA adalah peluncuran atau pendaratan wahana antariksa, pemindahan kontrol atas wahana ke pihak ketiga, penggunaan wahana yang belum diizinkan peluncurannya, dan melanjutkan operasi kegiatan keantariksaan yang ditangguhkan atau dihentikan akibat pelanggaran ketentuan administrasi atau perintah pengadilan. 
atau pencabutan otorisasi.

Operator yang mematuhi ketentuan FSOA akan mendapat bantuan finansial dari pemerintah atas kerugian akibat peluncuran atau pendaratan wahana antariksa terhadap pihak ketiga yang melebihi 60 juta Euro. ${ }^{83}$

Prancis memiliki tiga perangkat lunak untukmengkalkulasirisiko tabrakan, pecahan, dan/atau persebaran puing di fase tertentu misi antariksa. ${ }^{84}$ Terdapat pula program Conjunction Analysis and Evaluation, Assessment and Recommendations (CAESAR) untuk memonitor lokasi satelit, mengevaluasi risiko tabrakan, serta memberi rekomendasi untuk menghindari tabrakan. ${ }^{85}$

Centre National d'Études Spatiales (CNES) mengawasi kegiatan antariksa Prancis. Salah satu keberhasilan CNES adalah relokasi satelit EUTALSAT 4A dan Telecom 2D ke disposal orbit sesuai IADC Guidelines. ${ }^{86}$ CNES juga membentuk Collective for Space Care berisi best practice mitigasi space debris dengan pengumpulan data dari operator-operator. ${ }^{87}$

d. Jepang

Upaya mitigasi puing Jepang dilakukan Japan Aerospace Exploration Agency
$(\mathrm{JAXA})^{88}$ melalui penerapan JAXA Debris Mitigation Standard (sebelumnya NASDA STD-18). ${ }^{89}$ Standar ini mewajibkan pelaporan upaya mitigasi sampah antariksa dalam kegiatan antariksa yang diselenggarakan pihak swasta. JAXA Safety Review Board memiliki peninjauan berkala terhadap standar ini. ${ }^{90}$

Jepang berupaya membentuk hukum antariksa yang dapat memicu pertumbuhan industri antariksa melalui Basic Space Law 2008. Menyusul pembentukan hukum tersebut, dibentuk Basic Plan on National Space Policy 2009 yang diperbaharui tahun 2013 sebagai pedoman integrasi kebijakan antariksa Jepang. ${ }^{91}$ Dokumen ini menyatakan kewajiban untuk menaruh perhatian terhadap lingkungan (termasuk isu sampah antariksa) dalam perkembangan industri antariksa dan penggunaan sumber daya antariksa. ${ }^{92}$

Evaluasi Basic Plan 2009 mengindikasikan perlunya peningkatan Public-Private Partnership (PPP) ${ }^{93}$ dalam pengembangan industri yang mengaplikasikan teknologi satelit. ${ }^{94}$ Diperlukan pula koordinasi antara Ministry of Education, Culture, Sports, Science and Technology (MEXT) dengan

83 Pasal 13, 16-17 FSOA; Philippe Clerc, "French Space Operation Act: Lessons Learned from Its Implementation", dipresentasikan dalam France/Japan Seminar - Cross-cutting Perspectives in Space Law di sesi ke-55 LSC COPUOS, 7 April 2016, http://www.unoosa.org/ documents/pdf/copuos/lsc/2016/sem2-201.pdf, diakses 10 Februari 2019.

84 "DEBRISK", https://logiciels.cnes.fr/en/node/65?type=desc, diakses 10 Desember 2018; "ELECTRA", https://logiciels.cnes.fr/en/ node/83? type = desc, diakses 10 Desember 2018; "STELA", https://logiciels.cnes.fr/en/node/37?type=desc, diakses 10 Desember 2018.

85 Fernard Alby (CNES), "Overview on 2012 Space Debris Activities in France", dipresentasikan di STSC UNCOPUOS Februari 2013, http:// www.unoosa.org/pdf/pres/stsc2013/tech-10E.pdf, diakses 26 Desember 2018.

Ibid.

87 Philippe Clerc, Op. cit.; "General presentation of French activities and views for the long-term sustainability of outer space, in relation with the implementation of the first set of guidelines" http://www.unoosa.org/res/oosadoc/data/documents/2017/aac_105c_12017crp/ aac 105c 12017crp $260 \mathrm{html} / \mathrm{AC105}$ C1 2017 CRP26E.pdf, diakses 1 Januari 2019.

88 JAXA didirikan melalui Law Number 161 of 13 December 2002 sebagai gabungan Institute of Space and Astronautical Science (ISAS), National Aerospace Laboratory of Japan (NAL), dan National Space Development Agency of Japan (NASDA). "Introduction of JAXA", http:// global.jaxa.jp/about/jaxa/index.html, diakses 10 Desember 2018; Christophe Bonnal, Requirements for Debris Mitigation, dipresentasikan di IISL-ECSL Space Law Symposium 2014, Vienna, 24 Maret 2014, http://www.unoosa.org/pdf/pres/lsc2014/symp-05E.pdf, diakses 28 Desember 2018 .

89 Standar mitigasi Jepang mengacu pada hukum nasional, UN Guidelines, dan IADC Guidelines.

90 JAXA, Loc. cit.

91 Isamu Yamaguchi (Kementerian Luar Negeri Jepang), “Japan's Space Diplomacy and Regional Cooperation”, presentasi di The 25th Session of the Asia-Pacific Regional Space Agency Forum (APRSAF-25), Singapura, 9 November 2018, https://www.aprsaf.org/annual_meetings/ aprsaf25/data/8_SpaceCooperation/7-4_MOFA_APRSAF-25_Mr_Isamu_Yamaguchi_MOFA_Japan.pdf, diakses 10 Desember 2018.

92 Pasal 2.4 angka 6 Basic Plan on Space Policy, https://www8.çao.go.jp/space/plan/plan-eng.pdf, diakses 18 Desember 2018.

93 Koordinasi pemerintah dengan pihak swasta membantu menjamin ketersediaan data yang dapat digunakan untuk meningkatkan efisiensi teknologi di masa depan.

$94 \quad$ Ibid, hlm. 17. 
Ministry of Economy, Trade and Industry (METI). ${ }^{95}$ MEXT memiliki kontrol atas satelit yang digunakan untuk riset, sementara METI ditugaskan mengembangkan penggunaan satelit untuk tujuan komersial.

Space Activities Act 2016 merespon peningkatan kegiatan keantariksaan yang dilakukan badan non-pemerintah. ${ }^{96}$ Badan non-pemerintah harus mendapatkan perizinan dari Pemerintah Jepang (METI) setelah melalui pemeriksaan pemenuhan ketentuan teknis oleh JAXA. Terdapat pemeriksaan struktur satelit dan perencanaan pembuangan di tahap EOL untuk memastikan satelit tersebut tidak menimbulkan kontaminasi atau interferensi. ${ }^{97}$ Strict liability diterapkan untuk kerusakan terhadap pihak ketiga, dan ada kewajiban memiliki asuransi dengan dukungan finansial dari pemerintah Jepang jika jumlah kompensasi yang perlu diberikan pada pihak ketiga melebihi total yang ditanggung asuransi tersebut.

Implementasi hukum ini berjalan dengan baik. ${ }^{98}$ Seluruh peluncuran satelit oleh Jepang sejak tahun 1990 tidak menyebabkan gangguan di area terlindungi GEO kecuali disebabkan malfungsi atau kendala teknis lainnya.

Terlihat bahwa tiap negara memiliki pendekatan masing-masing dalam mengupayakan mitigasi antariksa. Misalnya, Jepang yang menyederhanakan lembagalembaganya demi efisiensi pembentukan hukum, walau hal ini berarti tiap peraturan normatif akan memerlukan peraturan teknis baru. Sementara itu, AS memilih untuk mendelegasikan pengawasan kegiatan antariksa pada lembaga-lembaga federal sesuai wewenangnya, sehingga mengemban beban untuk memastikan terjalinnya koordinasi yang baik antara lebaga-lembaga tersebut.

Rusia dan RRT mendorong kepentingnan nasional masing-masing dalam forum internasional ketika merumuskan panduan praktik mitigasi sampah antariksa. Keduanya juga membarui kebijakan teknisnya untuk menyelaraskan kebijakan nasional dengan standar internasional.

Keempat negara yang dibahas membentuk kebijakan nasional yang merujuk instrumen soft law, membarui kebijakan yang mengikuti perkembangan teknologi, dan memiliki mekanisme untuk mengikutsertakan pihak swasta, baik dalam perumusan hukum maupun pengumpulan data untuk menentukan best practice.

Tantangan implementasi pada dasarnya terdiri atas batasan finansial dan teknologi. Berdasarkan penjabaran state practice, dapat disimpulkan bahwa meski kerangka hukum negara-negara maju seperti Prancis dan Rusia sudah komprehensif, kepatuhan terhadap hukum masih bergantung pada keberhasilan penggunaan teknologi.

e. Pelajaran Berharga bagi Indonesia

Status Indonesia sebagai negara berkembang bukan menjadi halangan untuk memiliki visi kegiatan antariksa nasional. Melainkan sebaliknya, timbul

95 JAXA, "Space Debris Mitigation Mechanism in Japan: The Case of JAXA", dipresentasikan di 48th session Legal Subcommittee tahun 2009, http://www.unoosa.org/pdf/pres/lsc2009/pres-05.pdf, diakses 29 Desember 2018.

96 Koji Hara, "Current Status of Japan's Space Policy and Development of Legal Frameworks", presentasi dilakukan mewakili Kementerian Luar Negeri Jepang di sesi ke-56 LSC COPUOS tanggal 6 April 2017, http://www.unoosa.org/documents/pdf/copuos/lsc/2017/tech-09.pdf, diakses 28 November 2018 .

97 Ibid.

98 Vision for the Space Industry 2030 diadopsi untuk mendukung implementasi Space Activities Act. Fokus dokumen ini adalah sektor privat Jepang (industri penggunaan antariksa seperti big data, industri manufaktur, dan teknologi antariksa). Masanori Tsuruda (METI), “Japanese Space Industry Policy Overview - Space Industry in the Big Data Era”, https://www.eu-japan.eu/sites/default/files/imce/1._meti_tsuruda_1. pdf, diakses 29 Desember 2018. 
urgensi menyiapkan kerangka hukum dan pengembangan industri antariksa agar Indonesia tidak tertinggal oleh negara-negara lain.

Langkah awal untuk memiliki payung hukum antariksa nasional telah dilaksanakan. Indonesia perlu mencanangkan mitigasi sampah antariksa dalam Rancangan Peraturan Pemerintah sesuai mandat UU Keantariksaan dan mengejawantahkan mitigasi sampah antariksa dalam Peraturan Pemerintah dengan materi muatan perihal asuransi, kriteria peluncuran, peran serta masyarakat, dan standar keamanan dan keselamatan. LAPAN dan stakeholder lain memang harus memprioritaskan urutan perumusan berdasarkan urgensi yang ada. Namun, space debris perlu diikutsertakan dalam rezim hukum antariksa nasional karena akan berpengaruh pada liability yang ditanggung Indonesia dalam menyelenggaraan keantariksaan.

Peraturan seperti Permenkominfo memerlukan evaluasi berkala sebagaimana dilakukan Jepang. Indonesia perlu meninjau bilamana kriteria teknis yang ada cukup efektif sebagai tindakan preventif terhadap risiko timbulnya space debris.

Pemerintah juga dapat mendorong sektor swasta agar mengambil andil dalam perumusan hukum antariksa nasional sebagaimana dilakukan oleh AS. Perusahaan penyelenggara keantariksaan atau manufaktur satelit dapat memberi masukan, misalnya tentang kesulitan mendapat teknologi yang dapat meminimalkan risiko sampah antariksa.

Data mengenai kegiatan antariksa seperti efektivitas peluncuran, penggunaan satelit, dan dari perusahaan, Kemkominfo, dan LAPAN harus dikumpulkan dalam sebuah wadah. Nantinya, dapat dirumuskan panduan atau best practices mengikuti CNES untuk diakses pihak-pihak yang berkecimpung dalam kegiatan antariksa.

Indonesia juga memerlukan teknologi antariksa yang memadai. Sistem monitor, fasilitas peluncuran yang lebih canggih, dan satelit dengan penyimpanan bahan bakar yang stabil dapat meminimalkan risiko timbul sampah antariksa akibat ledakan. Akuisisi teknologi sepantasnya diikutsertakan dalam agenda kerja sama, baik bilateral, regional, maupun internasional.

Keaktifan dalam fora internasional yang membahas space debris memastikan bahwa Indonesia menjaga akses mendapatkan keuntungan dari upaya mitigasi yang telah berlangsung serta mempertahankan hak menyuarakan perspektif nasional selaku negara berkembang. Indonesia perlu memastikan space debris serta upaya mitigasinya menjadi mata acara yang terus dibahas di forum regional (APSCO dan APRSAF) dan internasional (COPUOS).

Upaya-upaya yang telah dibahas perlu dilakukan dengan runtut. Regulasi hanya dapat terlaksana dengan baik jika telah memperhitungkan perkembangan teknologi yang ada. Kerja sama akan maksimal jika dialog mampu mewakili kepentingan negara serta pihak swasta, dan teknologi yang dapat diperolehakanbermanfaatbagiperkembangan upaya nasional dalam memitigasi sampah antariksa. Jika keselarasan ini tercapai, maka menjadikan Indonesia sebagai negara yang mampu mengambil bagian serta memberi sumbangsih dalam upaya mitigasi sampah antariksa tidak lagi menjadi angan-angan belaka.

\section{Penutup}

Risiko sampah antariksa merupakan urgensi yang nyata. Penting untuk mengingat komitmen memitigasi space debris bersifat sukarela (voluntary) sehingga tidak mengikat (non-binding). Terlepas dari kesadaran internasional, sayangnya belum hadir hard law yang dapat mencetuskan 
tanggung jawab mengikat bagi aktor negara maupun swasta.

Alhasil, soft law dan standar teknis berperan besar dalam upaya mitigasi sampah antariksa. Dua contoh signifikan adalah IADC Guidelines dan ISO 24113 yang menjadi praktik banyak negara penyelenggara kegiatan antariksa dan organisasi internasional. Bahkan, pengadopsian ISO 24113 telah mengarah pada pembaruan beberapa instrumen hard law seperti dalam kasus ESA dan Rusia.

Sungguh disayangkan bahwa peraturan nasional perihal mitigasi sampah antariksa yang ada barulah bersifat preventif, dan hanya membahas perihal ganti rugi sebagai upaya penanggulangan. Masih terdapat ruang bertumbuh yang dapat digunakan sebagai kesempatan mempelajari praktik negara lain demi regulasi keantariksaan nasional yang lebih baik.

Keikutsertaan Indonesia dalam forum regional dan internasional pun perlu dimanfaatkan untuk mengusung pentingnya memitigasi sampah antariksa, baik dalam manifestasi hukum nasional maupun upaya akuisisi teknologi. Akhir kata, Indonesia memiliki banyak pekerjaan rumah jika ingin memiliki rezim hukum antariksa, yang dapat mengakomodasi upaya mitigasi sampah antariksa.

\section{DAFTAR PUSTAKA}

\section{A. Buku}

Contant-Jorgenson, Corinne, et al. (eds.), 2006, Cosmic Study on Space Traffic Management, International Academy of Astronautics (IAA), Paris.

Schrogl, Kai-Uwe, et al., 2018, Space Traffic Mangement: Towards A Roadmap for Implementation, International Academy of Astronautics (IAA), Paris.

\section{B. Artikel Jurnal}

Fatmawati, Nurul Sri, "Analisis Implementasi Pedoman PBB tentang Mitigasi Sampah Antariksa", Jurnal Analisis dan Informasi Kedirgantaraan, Vol. 9, No. 2, Desember 2012.

Mejia-Kaiser, Martha, "Informal Regulations and Practices in the Field of Space Debris Mitigation", Air and Space Law, Vol. 34 No. $1,2009$.

Supancana, Ida Bagus Rahmadi, "How the Progressive Development of Outer Space Law Affects the Formulation of National Space Legislation: The Experience of Indonesia", Air \& Space Law, Vol. 40 No. 1, 2015.

\section{Makalah/Pidato}

Von der Dunk, Frans G., 1992, "Liability versus Responsibility in Space Law: Misconception or Misconstruction?", dipublikasikan di Proceedings of the 34th Colloquium on the Law of Outer Space: 363-371.

\section{Artikel dalam Antologi dengan Editor}

Ardes, Runggu Prilia, et al., "Pertimbangan Yuridis dan Konsekuensi Pengelompokan RPP sebagai Amanat Undang-Undang Nomor 21 Tahun 2013 tentang Keantariksaan", dalam Nasution, Husni, et al., 2016, Kajian Kebijakan Penerbangan dan Antariksa: Hukum, Politik, Sosio-Ekonomi, Budaya, Pertahanan, Keamanan, In Media, Bogor, https://puskkpa.lapan.go.id/files_arsip/ Runggu_Pertimbangan_Yuridis_20162.pdf, diakses 10 Januari 2019.

Supriadhie, Anjar, "Penyebab Terjadinya Kerugian dan Tuntutan Tanggung Jawab dalam Penyelenggaraan Keantariksaan", dalam Euis Susilawati, et al., 2015, Kajian Kebijakan dan Hukum Kedirgantaraan, Mitra Wacana Media, Jakarta. 


\section{E. Internet}

Agapov, Vladimir M., "National Space Law and Policy of the Russian Federation", dipresentasikan di UN/CHINA/APSCO Workshop on Space Law, Beijing, 18 November 2014, http://www.unoosa.org/ documents/pdf/spacelaw/activities/2014/ pres12E.pdf, diakses 4 Januari 2019.

Alby, Fernard, "Overview on 2011 Space Debris Activities in France", http:/www.unoosa. org/pdf/pres/stsc2012/tech-23E.pdf, diakses 26 Desember 2018.

, "Overview on 2012 Space Debris Activities in France", dipresentasikan di STSC UNCOPUOS Februari 2013, http:/www. unoosa.org/pdf/pres/stsc2013/tech-10E.pdf, diakses 26 Desember 2018.

American Institute of Aeronautics and Astronautics (AIAA), "EnsuringU.S.Leadershipin Space”, https://www.aiaa.org/uploadedFiles/Whats_ New/EnsuringUSLeadershipInSpace FINAL.pdf, diakses 12 Januari 2019.

Asia-Pacific Regional Space Agency Forum (APRSAF), "Space Technology Working Group", http://aprsaf.org/working_groups/ st/, diakses 3 Maret 2019.

Bonnal, Christophe, Requirements for Debris Mitigation, dipresentasikan di IISL-ECSL Space Law Symposium 2014, Vienna, 24 Maret 2014, http://www.unoosa.org/pdf/ pres/lsc2014/symp-05E.pdf, diakses 28 Desember 2018.

Centre National d'Études Spatiales (CNES), "DEBRISK", https://logiciels.cnes.fr/en/ node/65? type $=$ desc, diakses 10 Desember 2018.

, “ELECTRA”, https://logiciels.cnes.fr/en/ node/83? type $=$ desc, diakses 10 Desember 2018.

"STELA", https://logiciels.cnes.fr/en/ node/37? type $=$ desc, diakses 10 Desember 2018.

Clerc, Philippe, "The French Space Operations Act", https://olemiss.edu/programs/spacelaw/ events/pdfs/2011/clerc-presentationgalloway.pdf, diakses 1 Januari 2019.

, "French Space Operation Act: Lessons Learned from Its Implementation", dipresentasikan dalam France/Japan Seminar - Cross-cutting Perspectives in Space Law di sesi ke-55 LSC COPUOS, 7 April 2016, http://www.unoosa.org/documents/pdf/ copuos/1sc/2016/sem2-201.pdf, diakses 10 Februari 2019.

Compendium of Space Debris Mitigation Standards Adopted by States and International Organizations (Compendium), 25 Februari 2019, http:/www.unoosa.org/oosa/en/ ourwork/topics/space-debris/compendium. html, diakses 28 Maret 2019.

Deffree, Suzanne, "Satellite scatters radioactive debris over Canada, January 24, 1978", https://www.edn.com/electronics-blogs/ edn-moments/4405598/Satellite-scattersradioactive-debris-over-Canada-January-24--1978, diakses 21 Februari 2019.

European Space Agency, ESA's Annual Space Environment Report 2017.

Hara, Koji, “Current Status of Japan's Space Policy and Development of Legal Frameworks", presentasi dilakukan mewakili Kementerian Luar Negeri Jepang di sesi ke-56 LSC COPUOS tanggal 6 April 2017, http://www. unoosa.org/documents/pdf/copuos/lsc/2017/ tech-09.pdf, diakses 28 November 2018.

Hara, Koji, “Current Status of Japan's Space Policy and Development of Legal Frameworks", presentasi dilakukan mewakili Kementerian Luar Negeri Jepang di sesi ke-56 LSC COPUOS tanggal 6 April 2017, http://www. unoosa.org/documents/pdf/copuos/lsc/2017/ tech-09.pdf, diakses 28 November 2018.

IADC, "Welcome to the Inter-Agency Space Debris Coordination Committee Website", https:// www.iadc-online.org/, diakses 31 Desember 2018.

International Standardization Organization (ISO), "All About ISO", https://www.iso.org/about- 
us.html, diakses 29 Maret 2019.

JAXA, "Introduction of JAXA", http://global. jaxa.jp/about/jaxa/index.html, diakses 10 Desember 2018.

, "Space Debris Mitigation Mechanism in Japan: The Case of JAXA", dipresentasikan di 48th session Legal Subcommittee tahun 2009, http://www.unoosa.org/pdf/pres/ lsc2009/pres-05.pdf, diakses 29 Desember 2018.

Jehn, Rüdiger, et al., "Impact of Space Debris Mitigation Requirements on the Mission Design of ESA Spacecraft, ESA Space Debris Office", hlm. 5, dipresentasikan di $7^{\text {th }}$ European Conference on Space Debris, Darmstadt, Jerman, tanggal 18-21 April 2017, https://conference.sdo.esoc.esa. int/proceedings/sdc7/paper/406/SDC7paper406.pdf, diakses 4 Januari 2019.

Johnson, Christopher D., "Committee on the Peaceful Uses of Outer Space: History, Structure, Agenda, and Current Work", dipresentasikan di Georgetown University Law Center tanggal 12 April 2017, https:// swfound.org/media/205800/chris-johnsoncopuos-lecture-at-georgetown-universitylaw-center-april-2017.pdf, diakses 30 Desember 2018.

Lembaga Antariksa dan Penerbangan Nasional (LAPAN), "Tugas Pokok dan Fungsi", https://lapan.go.id/index.php/subblog/ pages/2013/5/Tugas-Pokok-dan-Fungsi, diakses tanggal 12 Januari 2019.

Pandit, Rajat, "India shoots down live satellite to demonstrate anti-satellite missile capability", http://timesofindia. indiatimes.com/articleshow/68603800. cms? utm_source $=$ contentofinterest\&utm medium $=$ text\&utm_campaign $=$ cppst,$\quad 30$ Maret 2019.

Prancis, "General presentation of French activities and views for the long-term sustainability of outer space, in relation with the implementation of the first set of guidelines", http://www.unoosa.org/res/oosadoc/data/ documents/2017/aac_105c_12017crp/ aac_105c_12017crp_26_0_html/AC105_ C1_2017_CRP26E.pdf, diakses 1 Januari 2019.

Roscosmos, "Activities of the Russian Federation on Space Debris Research in 2016", dipresentasikan di sesi ke-55 STSC COPUOS, 30 Januari - 10 Februari 2017, http://www.unoosa.org/documents/pdf/ spacelaw/activities/2014/pres12E.pdf, diakses 4 Januari 2019.

Tranchard, Sandrine, "ISO Standards for A Safer, Cleaner Space", https://www.iso.org/ news/2013/10/Ref1784.html, diakses 30 Desember 2018.

Tsuruda, Masanori, "Japanese Space Industry Policy Overview - Space Industry in the Big Data Era", https://www.eu-japan.eu/sites/ default/files/imce/1._meti_tsuruda_1.pdf, diakses 29 Desember 2018.

Utomo, Yunanto Wiji, "Sosok Falcon 9, Roket yang Puingya Diduga Jatuh di Sumenep", https://sains.kompas.com/read/2016/09/27/ 09000081/sosok.falcon.9.roket.yang. puingnya.diduga.jatuh.di.sumenep, diakses 12 Mei 2018.

Yamaguchi, Isamu, “Japan's Space Diplomacy and Regional Cooperation", presentasi di The 25th Session of the Asia-Pacific Regional Space Agency Forum (APRSAF-25), Singapura, 9 November 2018, https://www. aprsaf.org/annual_meetings/aprsaf25/ data/8_SpaceCooperation/7-4_MOFA_ APRSAF-25_Mr_Isamu_Yamaguchi MOFA_Japan.pdf, diakses 10 Desember 2018.

\section{F. Peraturan Perundang-undangan}

Undang-Undang Republik Indonesia Nomor 36 Tahun 1999 tentang Telekomunikasi (Lembaran Negara Republik Indonesia Tahun 1999 Nomor 154, Tambahan Lembaran Negara Republik Indonesia Nomor 3881). 
Undang-Undang Republik Indonesia Nomor 21 Tahun 2013 tentang Keantariksaan (Lembaran Negara Republik Indonesia Tahun 2013 Nomor 133, Tambahan Lembaran Negara Republik Indonesia Nomor 5435).

Peraturan Pemerintah Nomor 53 Tahun 2000 tentang Penggunaan Spektrum Frekuensi Radio dan Orbit Satelit (Lembaran Negara Republik Indonesia Tahun 2000 Nomor 108, Tambahan Lembaran Negara Republik Indonesia Nomor 3981).

Peraturan Menteri Komunikasi dan Informatika Nomor 21 Tahun 2014 tentang Penggunaan Spektrum Frekuensi Radio untuk Dinas Satelit dan Orbit Satelit (Berita Negara Republik Indonesia Tahun 2014 Nomor 1013).

\section{G. Dokumen Resmi Lain}

Constitution and Convention of the International Telecommunication Union (United Nations, Treaty Series, Vol, 1825 No. 31251, 22 Desember 1992).

Convention of International Liability for Damage caused by Space Objects 1972 (United
Nations, Treaty Series, Vol. 961, No. 13810, 1 September 1972).

Convention on Registration of Objects Launched into Outer Space 1976 (United Nations, Treaty Series, Vol. 1023, No. 15020, 15 September 1976).

European Space Agency (ESA), Administrative Instruction on Space Debris Mitigation for Agency Projects (ESA/ADMIN/ IPOL(2014)2, 28 Maret 2014).

European Space Agency, ESA's Annual Space Environment Report 2017.

Prancis, Decree on Technical Regulation issued pursuant to Act No. 2008-518 of 3rd June 2008, 31 Maret 2011.

The Committee on the Peaceful Uses of Outer Space (COPUOS), 2011, "Forty eighth session: A Report on the International Interdisciplinary Congress on Space Debris".

Treaty on Principles Governing the Activities of States in the Exploration and Use of Outer Space, including the Moon and Other Celestial Bodies 1967 (United Nations, Treaty Series, Vol. 610, No. 8843, 10 Oktober 1967). 